Supporting Information for

\title{
Soluble Telluride-Based Molecular Precursor for Solution-Processed
}

\section{High-Performance Thermoelectrics}

Seungki Jo ${ }^{\dagger}$, Sun Hwa Park ${ }^{\ddagger}$,Hosun Shin ${ }^{\ddagger}$, Inseon Oh", Seung Hwae Heo ${ }^{\dagger}$, Hyeong Woo Ban ${ }^{\dagger}$, Hyewon Jeong ${ }^{\dagger}$, Fredrick Kim ${ }^{\dagger}$, Seungjun Choo ${ }^{\dagger}$, Da Hwi Gü, Seongheon Baek ${ }^{\dagger}$, Soyoung Cho ${ }^{\dagger}$,

Jin Sang Kim ${ }^{\S}$, Bong-Seo Kim " , Ji Eun Lee" ${ }^{\|}$, Seungwoo Song ${ }^{\ddagger}$, Jung-Woo Yoo ${ }^{\dagger}$, Jae Yong Song" and Jae Sung Son $* \dagger$

†School of Materials Science and Engineering, Ulsan National Institute of Science and Technology (UNIST), Ulsan 44919, Republic of Korea

${ }^{\ddagger}$ Center for Convergence Property Measurement, Korea Research Institute of Standards and Science (KRISS), Daejeon 34113, Republic of Korea

${ }^{\S}$ Center for Electronic Materials, Korea Institute of Science and Technology (KIST), Seoul 02792, Republic of Korea

"Energy Conversion Research Center, Korea Electrotechnology Research Institute (KERI), Changwon 51543, Republic of Korea

*E-mail: jsson@unist.ac.kr 


\section{Experimental details}

Chemicals: Ethylenediamine ( $>99 \%$ ), 1,2-ethanedithiol (>98 \%), antimony(III) telluride (99.96\%), Super-Hydride ${ }^{\circledR}$ solution (1.0M of lithium triethylborohidride in THF), acetonitrile (anhydrous, $99.8 \%$ ), tri- $n$-octylphosphine (90 \%), iron(III) acetylacetonate (99.99 \%), platinum(II) acetylacetonate (97\%), oleic acid (90\%), and oleylamine (technical grade, $70 \%$ ) were purchased from Sigma-Aldrich.

Synthesis of purified $\mathrm{Sb}_{2} \mathrm{Te}_{3}$ solution: The initial $\mathrm{Sb}_{2} \mathrm{Te}_{3}$ solution was prepared by dissolving $0.172 \mathrm{~g}$ of $\mathrm{Sb}_{2} \mathrm{Te}_{3}$ powder in a cosolvent of $5 \mathrm{~mL}$ of ethylenediamine and $0.5 \mathrm{~mL}$ of ethanedithiol. The solution was stirred for over 4 hours at $50{ }^{\circ} \mathrm{C}$ to dissolve the powder fully and to prevent the crystallization of the cosolvent. ${ }^{[29]} \mathrm{Then}, 0.5 \mathrm{~mL}$ of superhydride was injected into the solution and the mixture was stirred for 15-20 minutes. Next, the solute was precipitated by adding $40 \mathrm{~mL}$ of acetonitrile to $2.85 \mathrm{~mL}$ of the $\mathrm{Sb}_{2} \mathrm{Te}_{3}$ solution followed by centrifugation at 7800 rpm for $10 \mathrm{~min}$. The submerged solute was redispersed in $0.5 \mathrm{~mL}$ ethylenediamine and filtered through a $0.2 \mu \mathrm{m}$ PTFE filter. Tri- $n$-octylphosphine (TOP) amounting to $0.25 \mathrm{~mL}$ was injected in $1 \mathrm{~mL}$ of the redispersed solution and stirred for $90 \mathrm{~s}$. The supernatant TOP-Te solution was removed using a micropipette, and the residual TOP-Te was washed with toluene. For the toluene washing process, $2 \mathrm{~mL}$ of toluene was added to the TOP-treated solution and the mixture was stirred for $90 \mathrm{~s}$. Then, the supernatant toluene was removed using a micropipette, and $150 \mu \mathrm{L}$ of ethylenediamine was added to dilute the concentrated solution after toluene washing. The washing process was repeated thrice. The final solution was filtered through a $0.2 \mu \mathrm{m}$ filter. All processes were performed in a nitrogen filled glove box.

Synthesis of FePt nanoparticle: FePt nanoparticles were synthesized following the procedure reported by Nakaya et al. with slight alterations. ${ }^{33}$ The flask was heated under a nitrogen atmosphere from room temperature to $160{ }^{\circ} \mathrm{C}$ for $15 \mathrm{~min}$ for completely dissolve the precursors. After injecting 1,2 -hexadecanediol into the flask at $160{ }^{\circ} \mathrm{C}$, the solution was heated to $250^{\circ} \mathrm{C}$ for $10 \mathrm{~min}$.

Deposition of $\mathrm{Sb}_{2} \mathrm{Te}_{3}$ thin films: Glass and silicon substrates were prepared by washing with methanol, acetone and isopropanol, followed by $\mathrm{O}_{2}$ plasma treatment to hydrophilize the substrate. Polyimide substrates were washed with 
isopropanol. The superhydride-synthesized $\mathrm{Sb}_{2} \mathrm{Te}_{3}$ solution was spin-coated twice onto glass, silicon and polyimide substrates at $2000 \mathrm{rpm}$ for $40 \mathrm{~s}$. The first coated layer was dried at $70{ }^{\circ} \mathrm{C}$ for $10 \mathrm{~min}$ and subsequently annealed at $200{ }^{\circ} \mathrm{C}$ for 30 minutes on a hot plate. The second layer was dried at $70{ }^{\circ} \mathrm{C}$ for $10 \mathrm{~min}$ and subsequently annealed at $300{ }^{\circ} \mathrm{C}$ for 30 minutes on a hot plate. To prevent tellurium evaporation, thin films were annealed with $60 \mathrm{mg}$ of tellurium powder in a closed space.

Characterization of materials: Microstructural characterization was performed using scanning electron microscopy (Nova-NanoSEM230, FEI) operated at $10 \mathrm{kV}$ and transmission electron microscopy (JEM-2100, JEOL) operated at $200 \mathrm{kV}$. Elemental analysis was conducted via energy dispersive X-ray spectroscopy (EDS) using NovaNanoSEM230. Selective area electron diffraction (SAED) was performed using a JEM-2100. Fourier transform infrared spectra (FT-IR) were collected in transmission mode using a Varian 670/620-IR. Thermogravimetric analysis (TGA) measurements were made using TA Instruments Q500 at a heating rate of $10{ }^{\circ} \mathrm{C} \mathrm{min}^{-1}$ under a nitrogen flow rate of $100 \mathrm{~mL} \mathrm{~min}^{-1}$. X-ray diffraction patterns were collected using a Rigaku D/MAX2500V/PC with a wavelength of $1.5418 \AA$ ( $\mathrm{Cu} \mathrm{Ka}$ X-ray source). The size of the $\mathrm{Sb}_{2} \mathrm{Te}_{3}$ solutes was estimated from dynamic light scattering measurement on a Malvern Instruments Zeta Sizer Nano-ZS90. X-ray reflectivity (XRR) curves were measured using normal X-ray diffractometer (D8 discover, Bruker) equipped with parabolic multilayer X-ray mirror, and $\mathrm{X}$-ray wavelength of $\mathrm{Cu} \mathrm{K} \alpha$ line was used. The heat capacity of the sample was measured by sapphire method using DSC measurement (Q200, TA Instruments).

The density calculation of $\mathrm{Sb}_{2} \mathrm{Te}_{3}$ thin film $^{\mathrm{S} 1}$ :

The refractive index of X-ray in materials can be expressed as presented Eq (1)

$$
\mathrm{n}=1-\delta-\mathrm{i} \beta
$$

where $\delta$ and $\beta$ represent the dispersion and absorption, respectively. The $\delta$ and $\beta$ can be described as

$$
\begin{aligned}
& \delta=\frac{\lambda^{2} r_{e}}{2 \pi} \rho_{e} \\
& \beta=\frac{\lambda}{4 \pi} \mu
\end{aligned}
$$


Here, $\lambda$ is wavelength of $\mathrm{X}$-ray, $r_{\mathrm{e}}$ is the electron radius, $\rho_{\mathrm{e}}$ is the density of electron, and $\mu$ is attenuation of coefficient. Since surface of our $\mathrm{Sb}_{2} \mathrm{Te}_{3}$ film is mirror like, we can approximate that absorption of X-ray is negligible. Therefore by applying Snell's law and small angle approximation, critical angle can be expressed as

$$
1-\delta=\cos \theta_{c} \approx 1-\frac{\theta_{c}^{2}}{2}
$$

As shown Eq. (2) and Eq. (4), one can notice that we can find the value of electron density through measurement of critical angle. Using the value of electron density of our film, we can find the value of mass density as

$$
\rho_{m}=\frac{\rho_{e} A}{N_{A} Z}
$$

Here, $A$ is the atomic weight, $N_{\mathrm{A}}$ is Avogadro's number, and $Z$ is the atomic number.

TE property measurements: Temperature-dependent electrical conductivity and Seebeck coefficient of $\mathrm{Sb}_{2} \mathrm{Te}_{3}$ thin films were measured along the in-plane direction using commercial equipment (LSR-3, Linseis Inc.) in the temperature range of $300 \mathrm{~K}$ to $500 \mathrm{~K}$. Thermal conductivity was evaluated by a TDTR method (TF-LFA, Linseis Inc.) in the temperature range of $300 \mathrm{~K}$ to $500 \mathrm{~K}$. The method is a pump-probe optical technique and it enables to measure the cross-plane thermal conductivity of $\mathrm{Sb}_{2} \mathrm{Te}_{3}$ films. The optical reflectivity of the top surface changes as the surface temperature rises by heating with a pump beam. ${ }^{\mathrm{S} 2}$ Thermal conductivity was obtained by the fitting process between the experimental data and the theoretical temperature based on the heat conduction model as described in previous literatures. ${ }^{\mathrm{S} 2, \mathrm{S3}}$ The Hall measurement was carried out at room temperature by a Hall measurement system (HMS-5300, ECOPIA). The carrier concentration $\left(n_{\mathrm{h}}\right)$ and the mobility $\left(\mu_{\mathrm{h}}\right)$ were calculated using the measured Hall coefficient and electrical conductivity measured with Van der Pauw method.

The bending cycle test: $\mathrm{A} \mathrm{Sb}_{2} \mathrm{Te}_{3}$ thin film with $4.0 \mathrm{~mm}$ width and $13.4 \mathrm{~mm}$ length on polyimide substrate was attached on the acrylic cylinder. As the films were bent by manually applied stress, the two-probe resistance was measured simultaneously with a multimeter (Figure S12). 


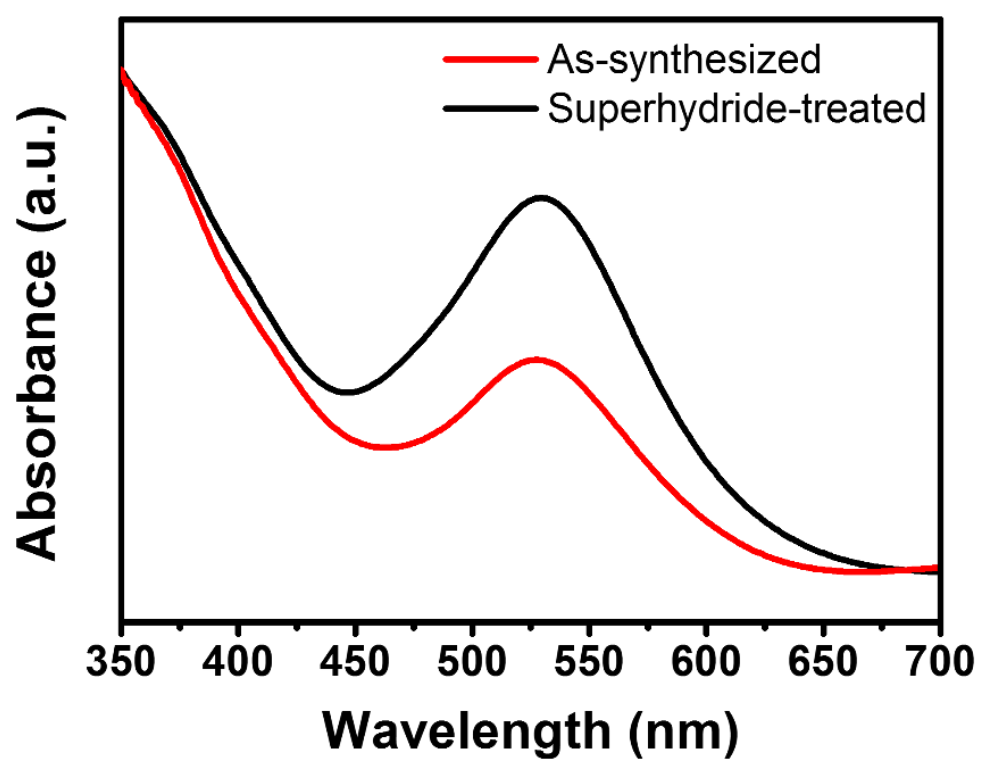

Figure S1. Absorption spectra of as-synthesized and superhydride-synthesized $\mathrm{Sb}_{2} \mathrm{Te}_{3}$ solution.
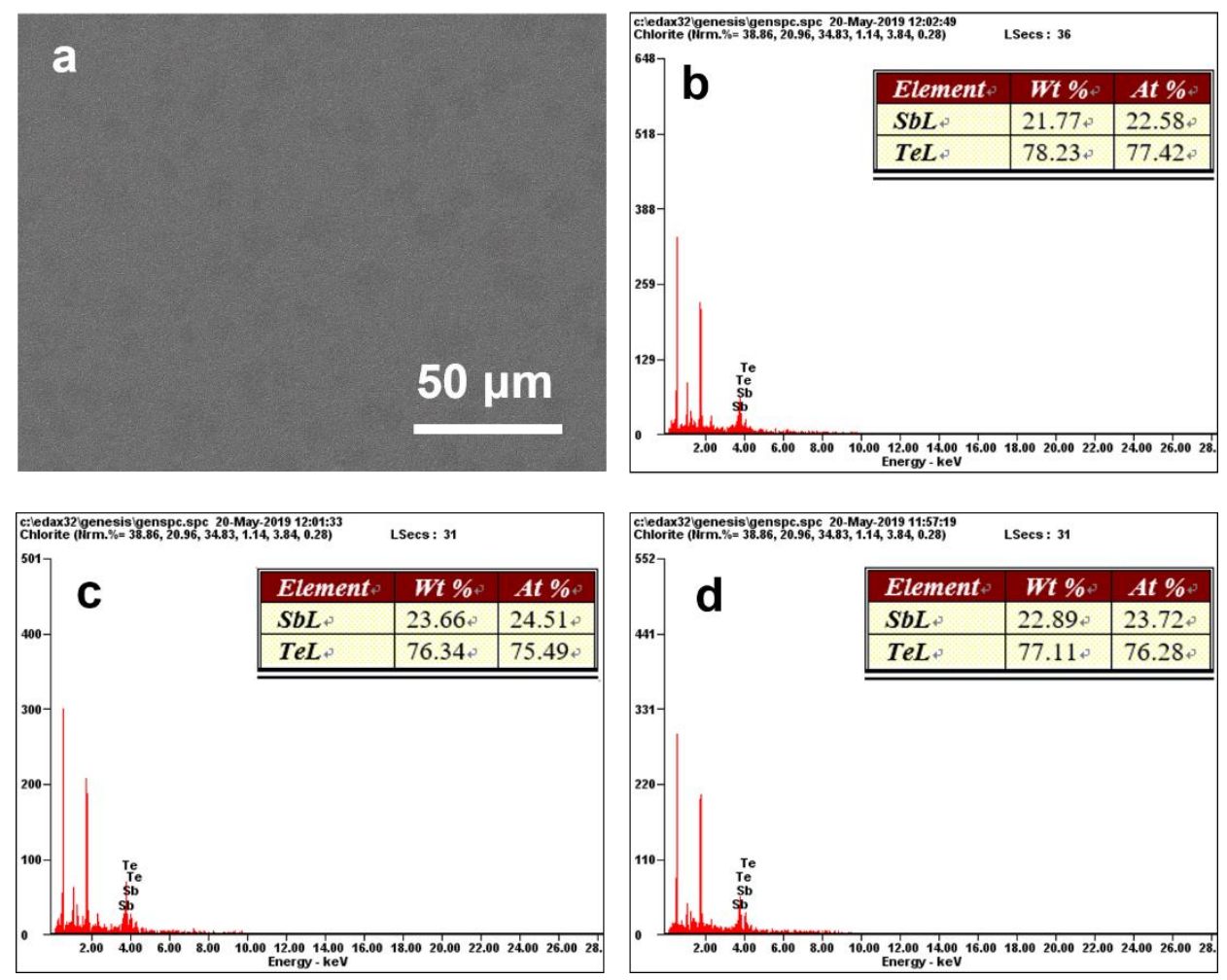

Figure S2. (a) SEM image of as-deposited thin film using the inks after superhydride reaction. (b-d) EDS spectra and atomic composition of $\mathrm{Sb}_{2} \mathrm{Te}_{7}$ of (a) at different points. 


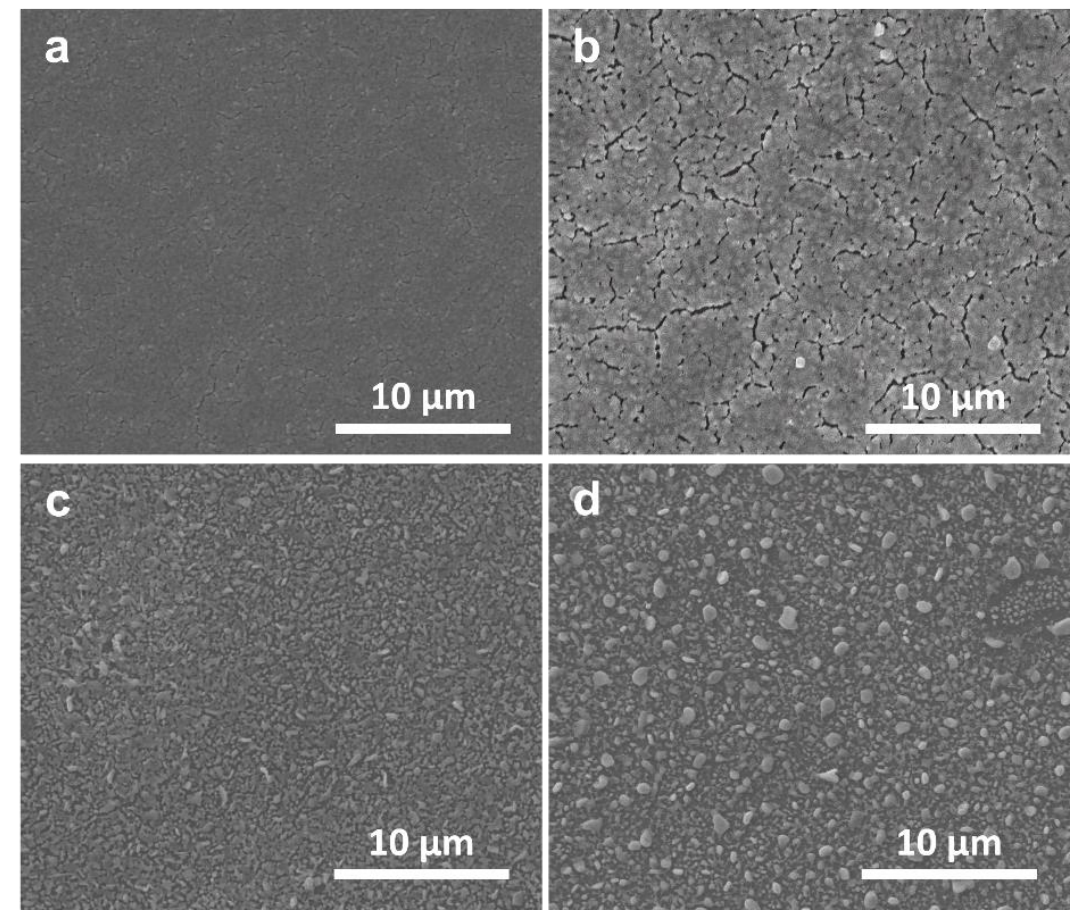

Figure S3. SEM images of thin film prepared using molecular $\mathrm{Sb}_{2} \mathrm{Te}_{7}$ solution, annealed at (a) $200{ }^{\circ} \mathrm{C}$, (b) $250{ }^{\circ} \mathrm{C}$, (c) $300{ }^{\circ} \mathrm{C}$ and (d) $350{ }^{\circ} \mathrm{C}$.

Table S1. The atomic compositions of thin-films annealed at various temperatures of Figure S3 estimated by EDS analysis.

\begin{tabular}{ccc}
\hline Sintering temperature $\left[{ }^{\circ} \mathrm{C}\right]$ & Sb content [at\%] & Te content [at\%] \\
\hline 200 & 21.66 & 78.34 \\
250 & 25.86 & 74.14 \\
300 & 39.02 & 60.98 \\
350 & 45.69 & 54.31 \\
\hline
\end{tabular}




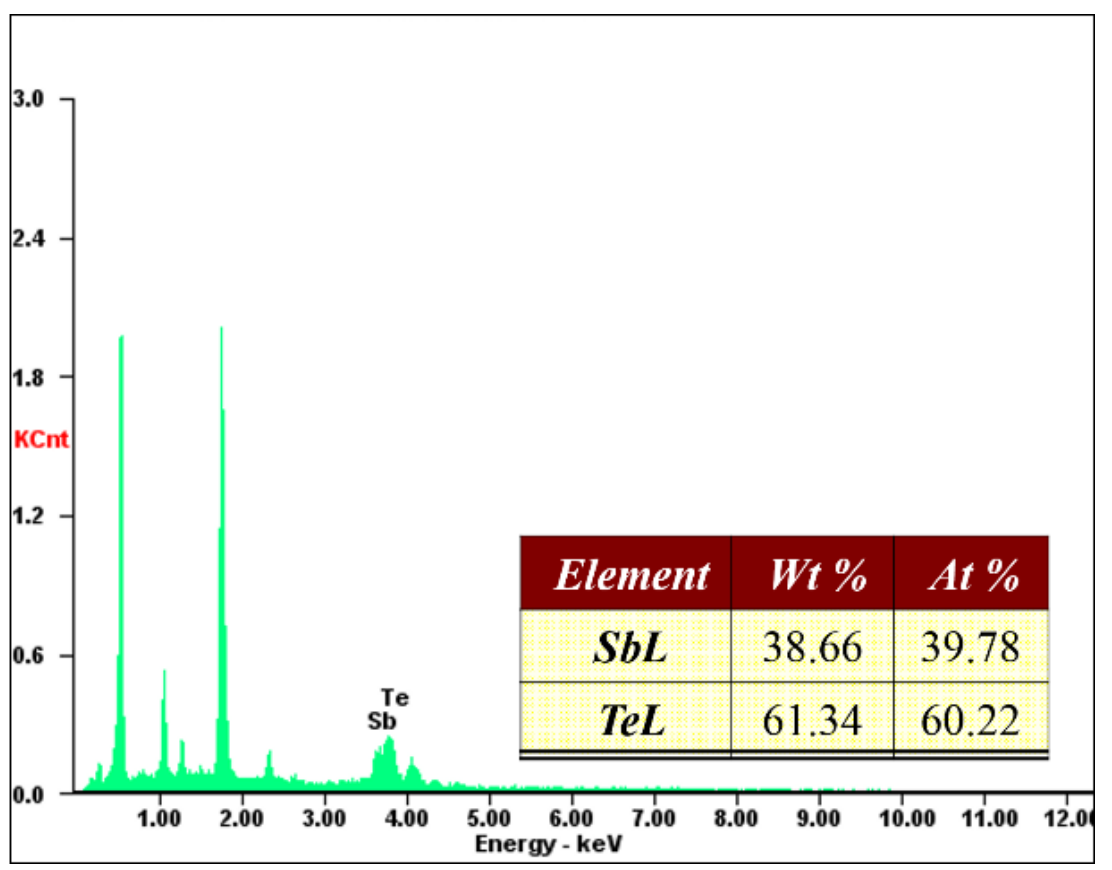

Figure S4. Atomic composition of a stoichiometric $\mathrm{Sb}_{2} \mathrm{Te}_{3}$ thin-film estimated by EDS spectra.
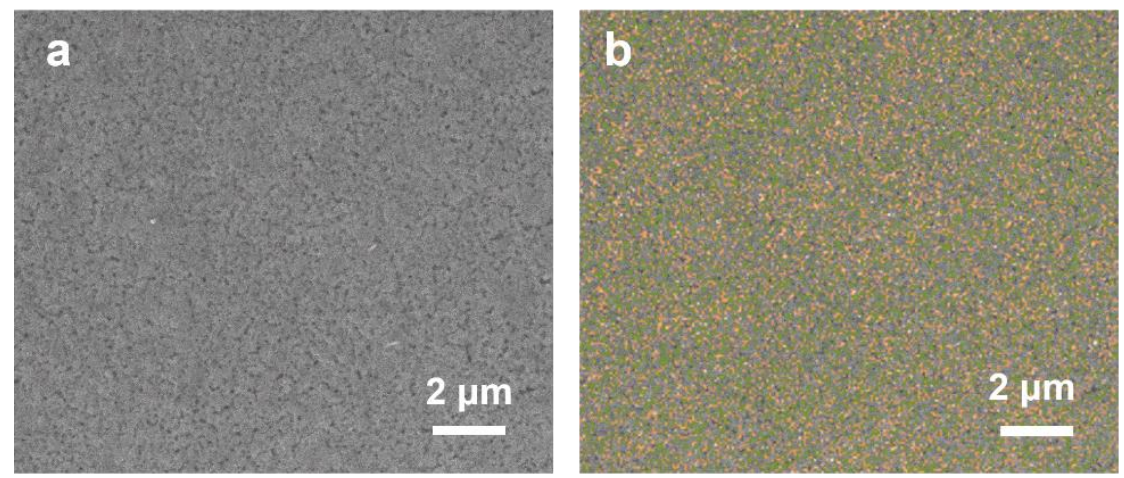

Sb
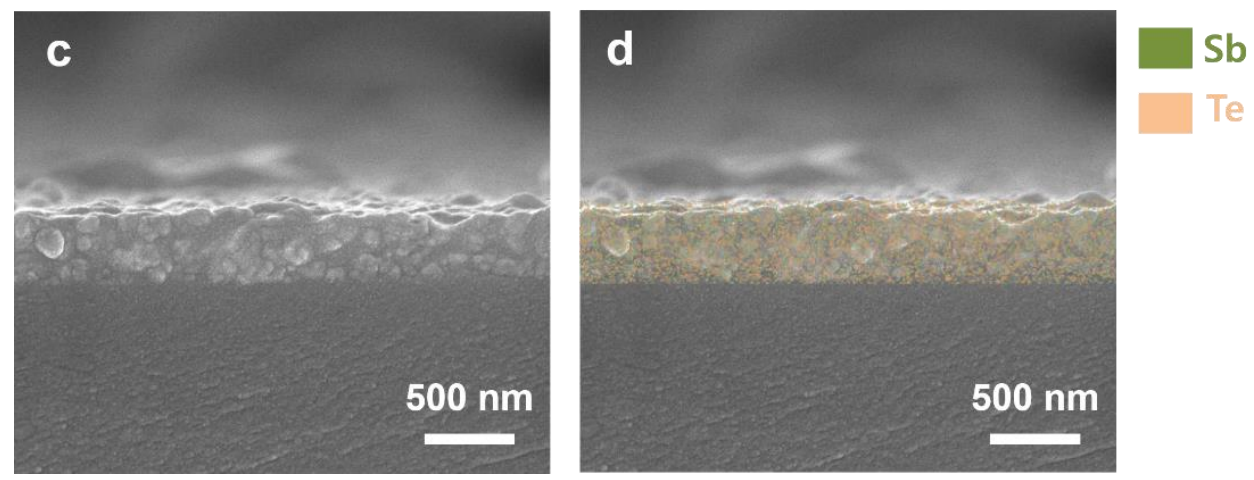

Figure S5. (a) SEM image of the $\mathrm{Sb}_{2} \mathrm{Te}_{3}$ thin film and (b) the corresponding EDS mapping image. (c) Cross sectional SEM image and (d) the corresponding EDS mapping image. 


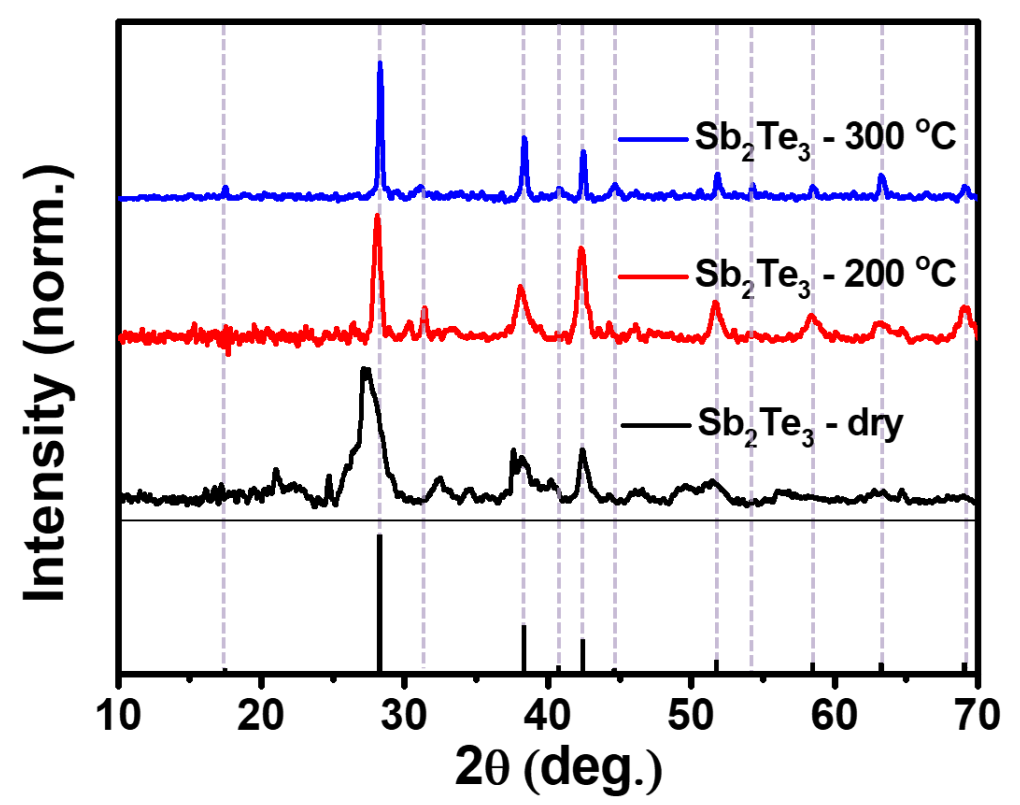

Figure S6. XRD patterns of $\mathrm{Sb}_{2} \mathrm{Te}_{3}$ thin films dried at room temperature and annealed at $200{ }^{\circ} \mathrm{C}$ and $300{ }^{\circ} \mathrm{C}$.

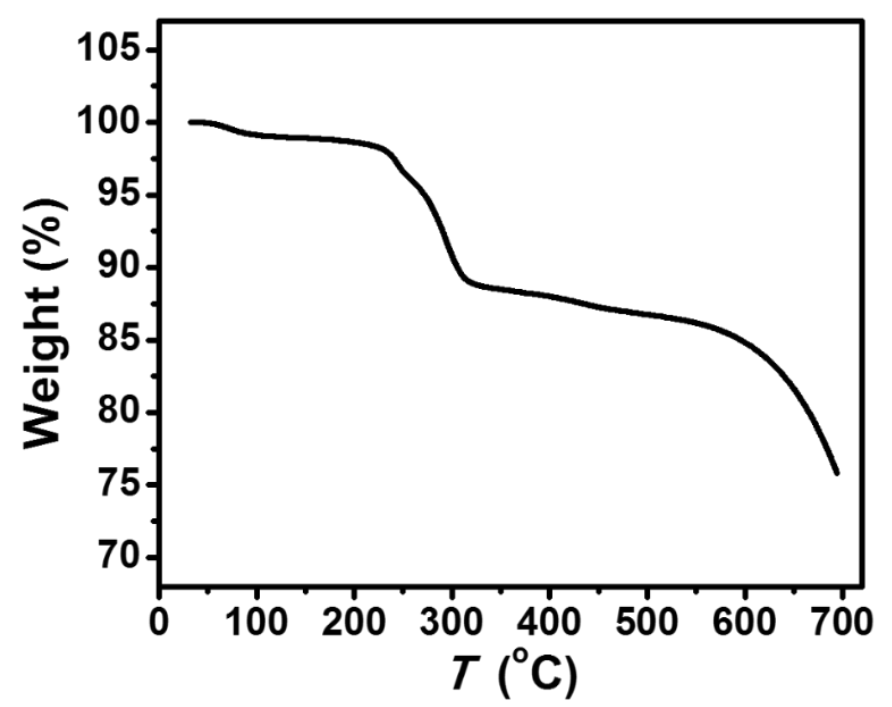

Figure S7. TGA analysis of the molecular $\mathrm{Sb}_{2} \mathrm{Te}_{3}$ precursor. 


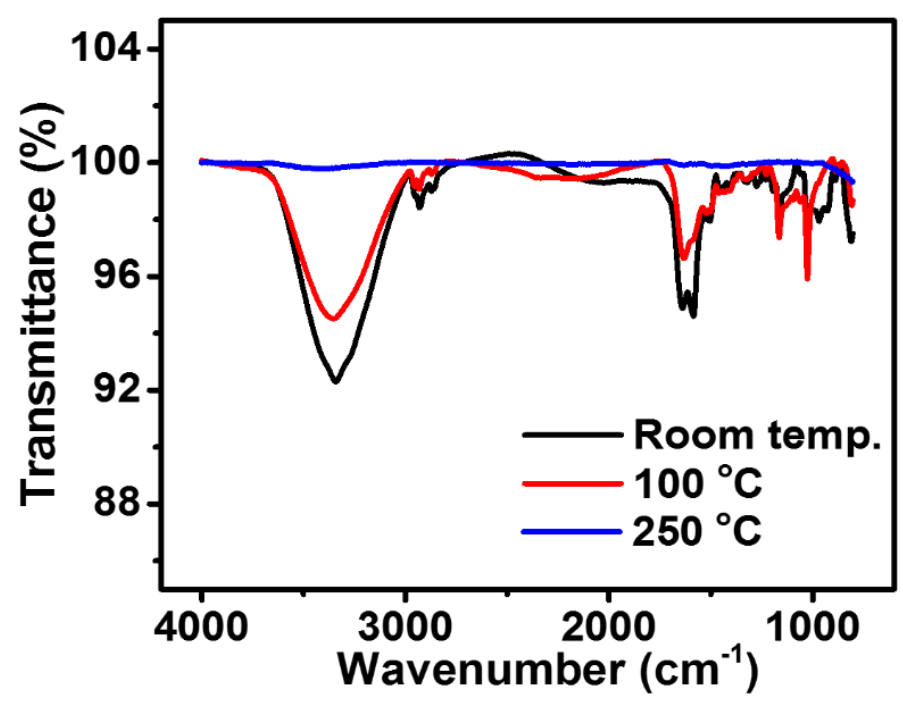

Figure S8. FT-IR spectra of molecular $\mathrm{Sb}_{2} \mathrm{Te}_{3}$ precursors dried at room temperature and annealed at $100{ }^{\circ} \mathrm{C}$ and $250{ }^{\circ} \mathrm{C}$. 


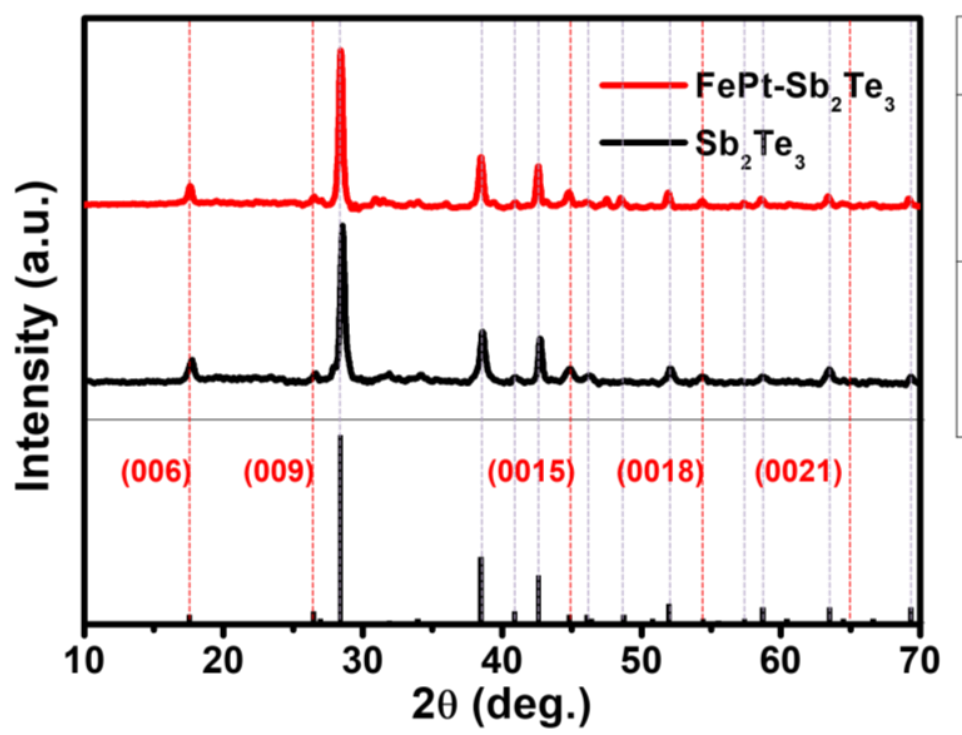

\begin{tabular}{|c|c|c|c|}
\hline & $P_{0}$ & $P(00)$ & $F$ \\
\hline $\begin{array}{c}\mathrm{FePt}^{\mathrm{F}} \\
\mathrm{Sb}_{2} \mathrm{Te}_{3}\end{array}$ & & 0.1599 & 0.0885 \\
\hline & \multirow{2}{*}{0.0783} & & \\
\cline { 1 - 3 } $\mathrm{Sb}_{2} \mathrm{Te}_{3}$ & & 0.1549 & 0.0831 \\
\hline
\end{tabular}

Figure S9. XRD patterns of $\mathrm{Sb}_{2} \mathrm{Te}_{3}$ and $\mathrm{FePt}$ nanoparticles embedded $\mathrm{Sb}_{2} \mathrm{Te}_{3}$ thin films. The calculated orientation factors $(F)$ using Lotgering's method are 0.0835 and 0.0903 , respectively.

To quantitatively estimate the degree of orientation along c-axis, the orientation factor $(F)$ of the thin films was calculated by Lotgering's method as expressed,

$$
\begin{gathered}
F=\frac{p-p_{0}}{1-p_{0}} \\
p=\frac{\sum I(00 l)}{\sum I(h k l)} \\
p_{0}=\frac{\sum I_{0}(00 l)}{\sum I_{0}(h k l)}
\end{gathered}
$$

where $p$, and $p_{0}$ are the relative quantity of $(00 l)$ reflections to sum of all reflections for the sample and the reference, respectively. $I$, and $I_{0}$ represent the intensities of the XRD peaks for the sample and the reference. Accordingly, $F$ varies from 0 for the fully-isotropic sample to unity for the fully-oriented sample. The value of $p_{0}$ was estimated from the reference (JCPDS No. 00-015-0874), exhibiting 0.0783.Based on this value, the estimated $F$ of the fabricated $\mathrm{Sb}_{2} \mathrm{Te}_{3}$ thin film marked 0.0831 , close to 0 , indicating almost randomly oriented grains. 

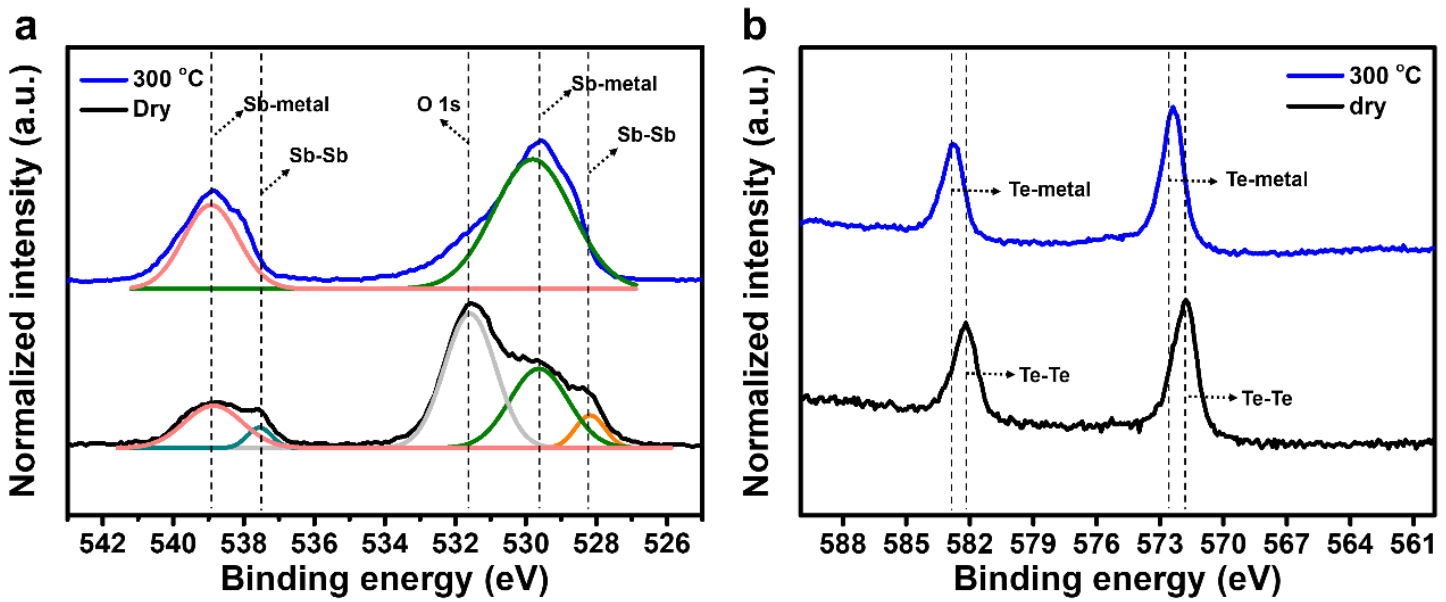

Figure S10. XPS spectra of (a) Sb $3 \mathrm{~d}$ and (b) $\mathrm{Te} 3 \mathrm{~d}$ for $\mathrm{Sb}_{2} \mathrm{Te}_{3}$ thin films dried at $70{ }^{\circ} \mathrm{C}$ and heat treated at $300{ }^{\circ} \mathrm{C}$. 


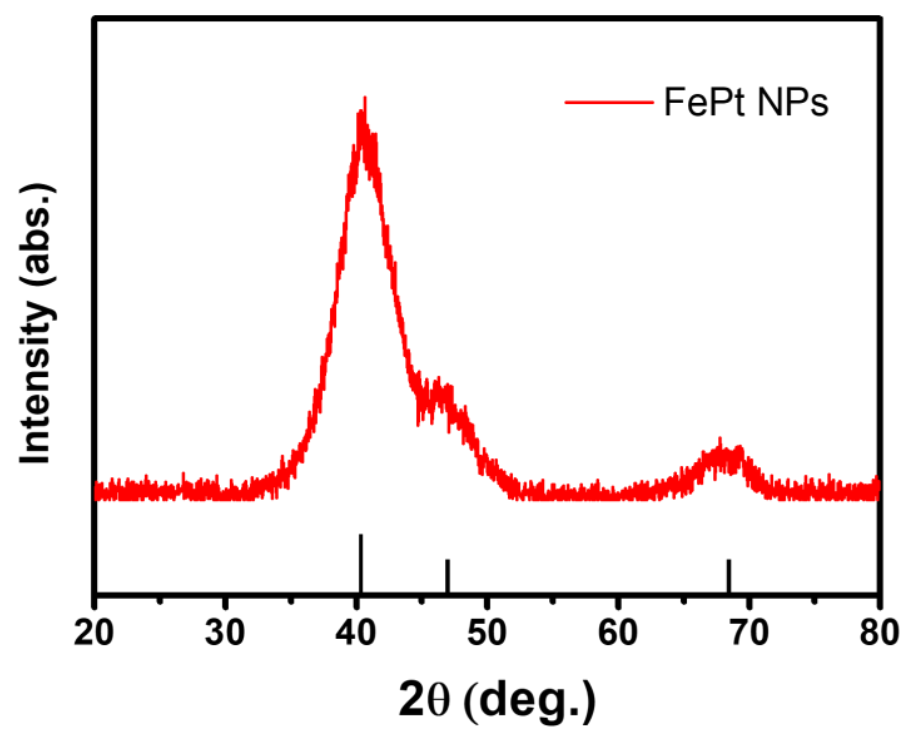

Figure S11. XRD pattern of as-synthesized FePt nanoparticles.
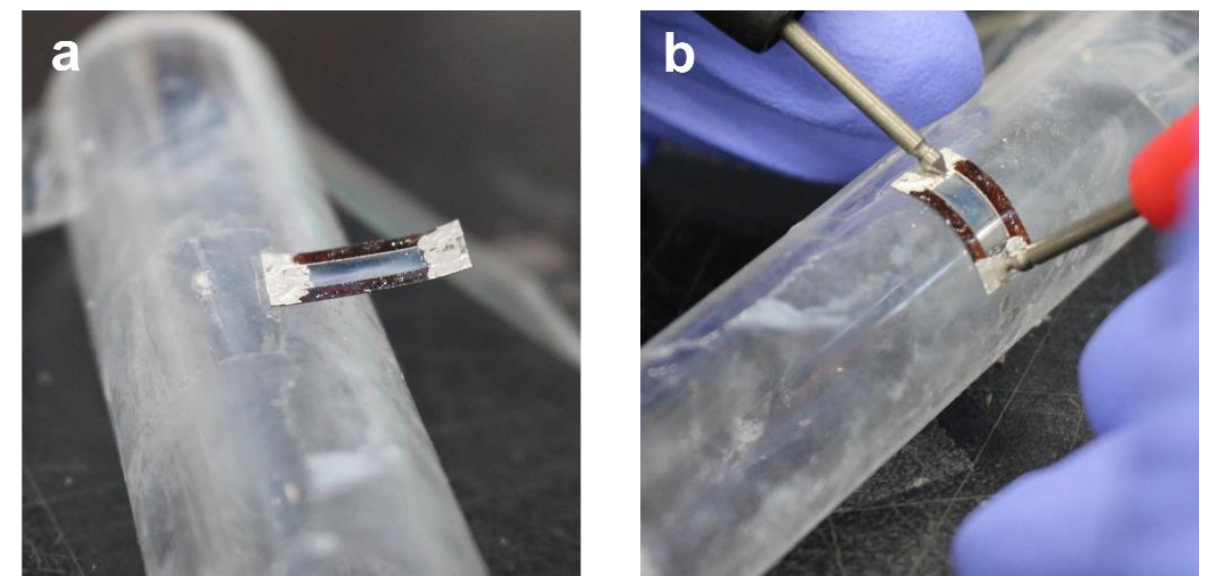

Figure S12. Photographs of $\mathrm{Sb}_{2} \mathrm{Te}_{3}$ thin film (a) attached on acrylic cylinder with bending radius of $10 \mathrm{~mm}$ and (b) where the two-probe resistance is being measured. 


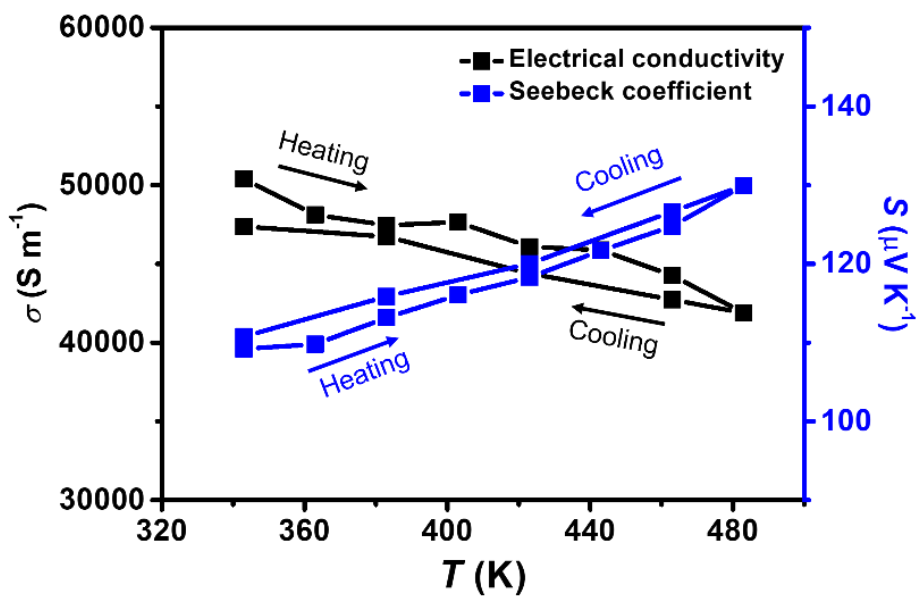

Figure S13. Photographs of $\mathrm{Sb}_{2} \mathrm{Te}_{3}$ thin film (a) attached on acrylic cylinder with bending radius of $10 \mathrm{~mm}$ and (b) where the two-probe resistance is being measured.

Table S2. Carrier concentration and mobility of $\mathrm{Sb}_{2} \mathrm{Te}_{3}$ thin films measured at room temperature.

\begin{tabular}{ccc}
\hline Samples & Carrier concentration $\left[\mathrm{cm}^{-3}\right]$ & Mobility $\left[\mathrm{cm}^{2} \mathrm{~V}^{-1} \mathrm{~s}^{-1}\right]$ \\
\hline $\mathrm{Sb}_{2} \mathrm{Te}_{3}$ & $1.66 \times 10^{20}$ & 17.5 \\
$\mathrm{FePt}^{2} \mathrm{Sb}_{2} \mathrm{Te}_{3}$ & $1.77 \times 10^{20}$ & 16.3 \\
\hline
\end{tabular}




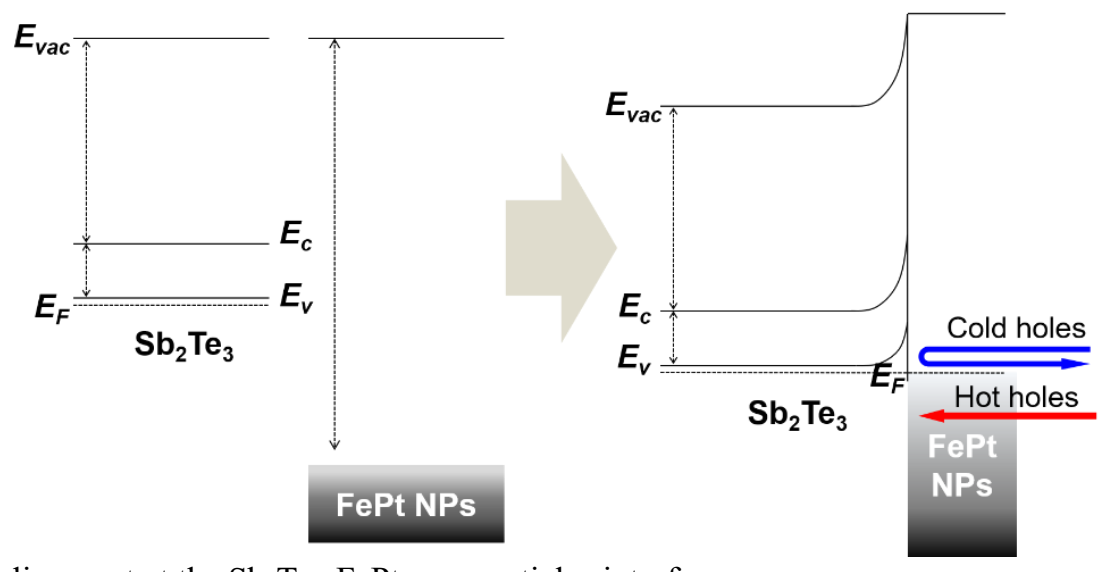

Figure S14. Band alignment at the $\mathrm{Sb}_{2} \mathrm{Te}_{3}-\mathrm{FePt}$ nanoparticles interface.
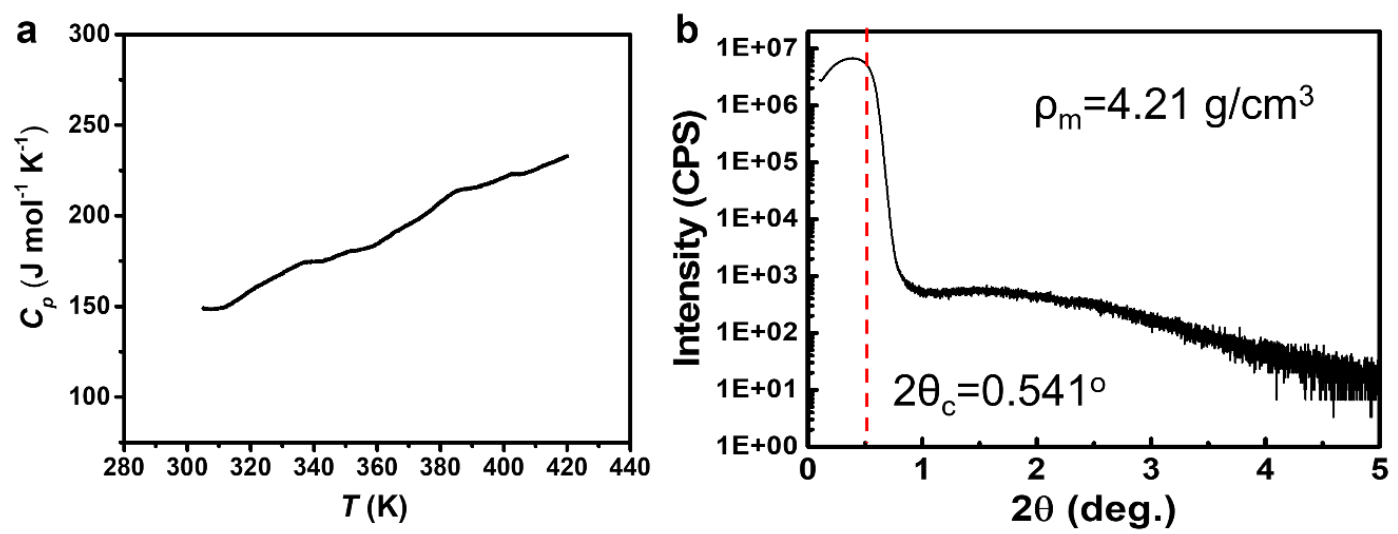

Figure S15. (a) Temperature dependent molar heat capacity $\left(C_{\mathrm{p}}\right)$ and (b) X-ray reflectivity (XRR) profile of $\mathrm{Sb}_{2} \mathrm{Te}_{3}$ thin film. 


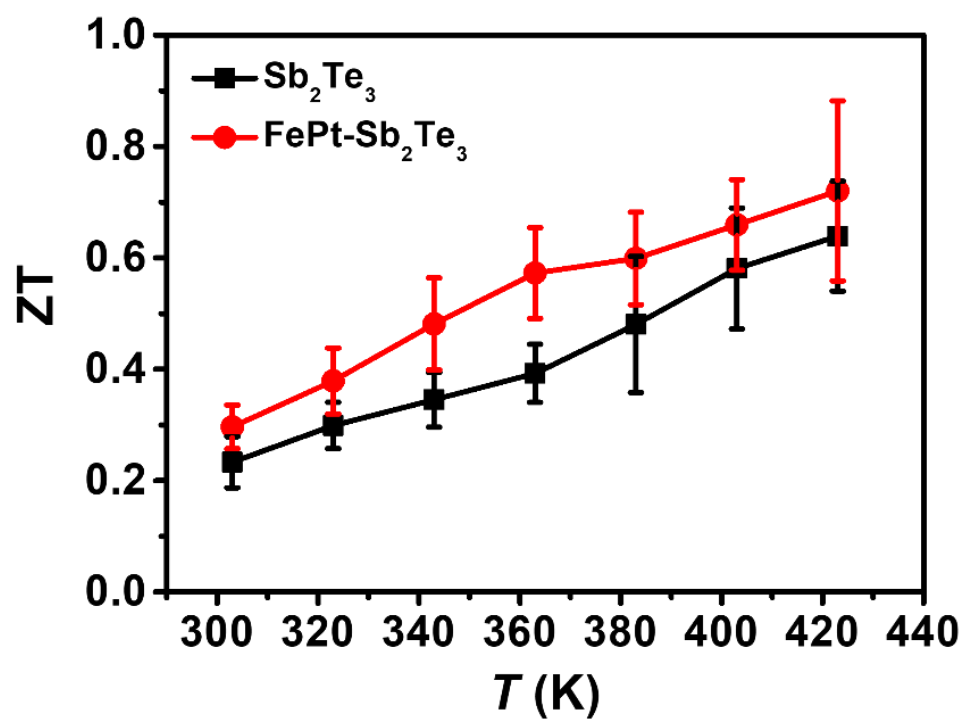

Figure S16. Estimated ZT values of $\mathrm{Sb}_{2} \mathrm{Te}_{3}$ and $\mathrm{FePt}-\mathrm{Sb}_{2} \mathrm{Te}_{3}$ thin films. 
Table S3. Thermoelectric properties of all-solution-processed bismuth and antimony chalcogenide-based thin films at room temperature. Thermal properties measured along perpendicular direction are marked by ' $\perp$ '. Thermal properties measured on pellet samples are marked by 'pellet'.

\begin{tabular}{|c|c|c|c|c|c|c|}
\hline Materials & $\begin{array}{c}\text { Electrical } \\
\text { conductivity } \\
{\left[\mathrm{S} \mathrm{cm}^{-1}\right]}\end{array}$ & $\begin{array}{c}\text { Seebeck } \\
\text { coefficient } \\
{\left[\mu \mathrm{K}^{-1}\right]}\end{array}$ & $\begin{array}{c}\text { Power } \\
\text { factor } \\
{\left[\mu \mathrm{W} \mathrm{cm} \mathrm{K}^{-2}\right]}\end{array}$ & $\begin{array}{c}\text { Thermal } \\
\text { conductivity } \\
{\left[\mathrm{W} \mathrm{m} \mathrm{K}^{-1}\right]}\end{array}$ & $\mathrm{ZT}_{\max }$ & Ref. \\
\hline $\mathrm{Sb}_{2} \mathrm{Te}_{3}$ & 73 & 116 & 0.98 & - & - & S4 \\
\hline $\mathrm{Pt}-\mathrm{Sb}_{2} \mathrm{Te}_{3}$ & 44 & 152 & 1.02 & - & - & S4 \\
\hline $\mathrm{Sb}_{2} \mathrm{Te}_{3}$ & 39 & 124 & 0.60 & - & - & S5 \\
\hline $\mathrm{Sb}_{2} \mathrm{Te}_{3}$ & 70 & 114 & 0.91 & - & - & S5 \\
\hline $\mathrm{Ag}_{31} \mathrm{Sb}_{19} \mathrm{Te}_{50}$ & 56 & 135 & 1.02 & - & - & S5 \\
\hline $\mathrm{Ag}_{34} \mathrm{Sb}_{18} \mathrm{Te}_{48}$ & 107 & 93 & 0.93 & - & - & S5 \\
\hline $\mathrm{Sb}_{2} \mathrm{Te}_{3}$ & 56 & 84 & 0.40 & - & - & S6 \\
\hline $\mathrm{Ag}-\mathrm{Sb}_{2} \mathrm{Te}_{3}$ & 350 & 103 & 3.71 & $\sim 0.44(\perp)$ & 0.23 & S6 \\
\hline $\mathrm{Sb}_{2} \mathrm{Te}_{3}-\mathrm{Te}$ & $\sim 280$ & $\sim 146$ & $\sim 6.0$ & $\sim 1.1(\perp)$ & 0.3 & S7 \\
\hline$(\mathrm{Bi}, \mathrm{Sb})_{2} \mathrm{Te}_{3}$ & 260 & 250 & 16.3 & $\sim 1.5$ (pellet) & 0.63 & S8 \\
\hline$(\mathrm{Bi}, \mathrm{Sb})_{2}\left(\mathrm{Te}_{0.9} \mathrm{Se}_{0.1}\right)_{3}$ & 87 & 170 & 2.51 & - & - & S8 \\
\hline $\mathrm{Bi}_{2} \mathrm{Se}_{3}$ & $\sim 480$ & $\sim-100$ & $\sim 4.8$ & $\sim 0.37(\perp)$ & 0.40 & S9 \\
\hline $\mathrm{Bi}_{2} \mathrm{TeSe}_{2}$ & $\sim 390$ & $\sim-120$ & $\sim 5.6$ & $\sim 0.42(\perp)$ & 0.39 & S9 \\
\hline $\mathrm{Bi}_{2} \mathrm{Te}_{2} \mathrm{Se}$ & $\sim 85$ & $\sim-195$ & $\sim 3.23$ & $\sim 0.48(\perp)$ & 0.22 & s9 \\
\hline $\mathrm{Bi}_{2} \mathrm{Te}_{3}$ & $\sim 120$ & $\sim-68$ & $\sim 0.55$ & $\sim 1.39(\perp)$ & $\sim 0.01$ & S9 \\
\hline $\mathrm{Sb}_{2} \mathrm{Te}_{3}$ & 465 & 106 & 5.18 & $\sim 0.67(\perp)$ & 0.63 & $\begin{array}{l}\text { This } \\
\text { work }\end{array}$ \\
\hline 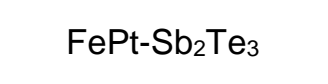 & 463 & 107 & 5.27 & $\sim 0.57(\perp)$ & 0.70 & $\begin{array}{l}\text { This } \\
\text { work }\end{array}$ \\
\hline
\end{tabular}




\section{References}

(S1) Veldhuis, S. A., Brinks, P., Stawski, T. M., Göbel O. F., ten Elshof, J. E. A facile method for the density determination of ceramic thin films using X-ray reflectivity. J. Sol-Gel. Sci. Techno. 2014, 71, 118.

(S2) Cahill, D.G. Analysis of heat flow in layered structures for time-domain thermoreflectance. Rev. Sci. Instrum. 2004, 75, 5119-5122.

(S3) Feldman, A. Algorithm for solutions of the thermal diffusion equation in a stratified medium with a modulated heating source. High Temp.-high Press. 1999, 31, 293.

(S4) Ko, D.-K.; Kang, Y.; and Murray, C.B. Enhanced thermopower via carrier energy filtering in solutionprocessable $\mathrm{Pt}-\mathrm{Sb}_{2} \mathrm{Te}_{3}$ nanocomposites. Nano lett. 2011, 11, 2841-2844.

(S5) Zhang, Y.; Snedaker, M.L.; Birkel, C.S.; Mubeen, S.; Ji, X.; Shi, Y.; Liu, D.; Liu, X.; Moskovits, M.; and Stucky, G.D. Silver-based intermetallic heterostructures in $\mathrm{Sb}_{2} \mathrm{Te}_{3}$ thick films with enhanced thermoelectric power factors. Nano lett. 2012, 12, 1075-1080.

(S6) Dun, C.; Hewitt, C.A.; Li, Qi.; Xu, J.; Schall, D.C.; Lee, H.; Jiang, Q.; and Carroll, D.L. 2D chalcogenide nanoplate assemblies for thermoelectric applications. Adv. Mater. 2017, 29, 1700700.

(S7) Zhang, Y.; Bahk, J.-H.; Lee, J.; Birkel, C.S.; Snedaker, M.L.; Liu, D.; Zeng, H.; Moskovits, M.; Shakouri, A.; and Stucky, G.D. Hot carrier filtering in solution processed heterostructures: A paradigm for improving thermoelectric efficiency. Adv. Mater. 2014, 26, 2755-2761.

(S8) Kovalenko, M.V.; Spokoyny, B.; Lee, J.-S.; Scheele, M.; Weber, A.; Perera, S.; Landry, D.; and Talapin, D.V. Semiconductor nanocrystals functionalized with antimony telluride zintl ions for nanostructured thermoelectrics. J. Am. Chem. Soc. 2010, 132, 6686-6695.

(S9) Wang, R.Y.; Feser, J.P.; Gu, X.; Yu, K.M.; Segalman, R.A.; Majumdar, A.; Milliron, D.J.; and Urban, J.J. Universal and solution-processable precursor to bismuth chalcogenide thermoelectrics. Chem. Mater. 2010, 22, 1943-1945. 